\title{
A importância do desporto de alto rendimento na inclusão social dos cegos: Um estudo centrado no Instituto Benjamin Constant - Brasil
}

\author{
The importance of high performance sports in social inclusion of blind \\ people: A study centered on Benjamin Constant Institute - Brazil
}

\author{
R. Pereira, R. Osborne, A. Pereira, S.I. Cabral
}

ARTIGO ORIGINAL | ORIGINAL ARTICLE

\begin{abstract}
A população de pessoas deficientes vem crescendo a cada dia, gerando problemáticas sociais que interferem diretamente na qualidade de vida deste segmento. O objetivo dessa pesquisa foi investigar o esporte de alto rendimento como contribuição para inclusão social de atletas cegos do Instituto Benjamin Constant. Observou-se que os alunos egressos do Instituto, até duas décadas atrás, não davam prosseguimento aos seus estudos, embora gozassem de oportunidade igualitária e constitucional como cidadão brasileiro. Foram entrevistados dez atletas cegos egressos do Instituto, que estudaram entre 1994 e 1998, tendo na época da pesquisa a condição de atletas de alto rendimento e ao mesmo tempo cidadãos, que trabalham, estudam e são independentes. A pesquisa utilizou o método qualitativo, empregando como instrumento de investigação a entrevista semi-estruturada (Flick, 2005; Ruquoy, 2005). Para tratamento dos dados utilizou-se a técnica de "Análise de Conteúdo" (Minayo, Deslandes, Neto, \& Gomes, 2002). Os resultados foram organizados em torno de três categorias: a importância do esporte, orientação e mobilidade, e a vida antes e depois de ser atleta. A pesquisa concluiu que o esporte de alto rendimento contribuiu para a inclusão social de todos os entrevistados. Seus depoimentos responsabilizam o esporte como fator primordial para realização de parte de seus ideais, sugerindo esta prática em todas as instituições de ensino especial.

Palavras-chave: cegos, esporte, inclusão social
\end{abstract}

RESUMO

ABSTRACT

The population of disabled people is growing each day, producing social problems that interfere straightly in the capacity of life of this segment. The objective of this inquiry was to investigate the high performance sport as a contribution for social inclusion of blind athletes of the Benjamin Constant Institute. It was observed that the previous students of the Institute, up to two decades before, did not proceed in their studies, although they had egalitarian and constitutional opportunity as a Brazilian citizen. Ten blind athletes, previous students of the Institute from 1994 to 1998, were interviewed. They had, at the time of the research, the high performance athletes' condition and were at the same time citizens, who work, study and are independent. The inquiry used the qualitative method, employing the semi-structured interview as the instrument of investigation (Flick, 2005; Ruquoy, 2005). The "Content Analysis" technique was used to treat the data (Minayo et al., 2002). The results were organized around three categories: the importance of the sport, orientation and mobility, and life before and after being an athlete. The inquiry concluded that high performance sport contributed to the social inclusion of all the interviewed ones. His testimonies hold the sport responsible as a primordial factor for realization of part of his ideals, suggesting this practice in all the institutions of special teaching.

Keywords: blind men, sport, social inclusion

Submetido: 24.01.2012 | Aceite: 24.08.2012

Ramon Pereira, Soraia Izabel Cabral. Instituto Benjamin Constant, Rio de Janeiro, Brasil.

Renata Osborne. Universidade Salgado de Oliveira, Niterói, Brasil.

Antonino Pereira. Escola Superior de Educação de Viseu, Viseu, Portugal.

Endereço para correspondência: Antonino Pereira, Escola Superior de Educação de Viseu, Rua Maximiano Aragão, 3504-501 Viseu, Portugal.

E-mail: apereira@esev.ipv.pt 
A sociedade muitas vezes valoriza de tal forma a aparência das pessoas, que a sua essência fica em segundo plano. Quintão (2005) e Rechineli, Porto, e Moreira (2008) retratam bem esta ideia descrevendo a impatia da sociedade quando deparada com a deformidade de um corpo, sendo esta uma das primeiras barreiras a serem ultrapassadas.

Assim sendo, as conquistas alcançadas pelas pessoas deficientes têm se arrastado através de muitas décadas. No caso específico do deficiente visual no Brasil, foi o Instituto Benjamin Constant (IBC) que em 1854 deu início ao atendimento educacional dos cegos deste país e o faz até os dias de hoje (Vieira, 1998). Entretanto, apesar deste avanço nota-se que persiste ainda algumas barreiras que precisam ser removidas. É o caso, por exemplo, da inclusão social.

Por muitos anos, os alunos que concluíam o primeiro grau (oitava série), não tinham perspectiva de vida fora da instituição, consequentemente permaneciam vagando durante o dia nos corredores e bancos do IBC, voltando para suas casas durante a noite, regressando para o IBC ao amanhecer. A grande maioria vivia de esmolas e benefícios do governo. Apenas um reduzido contingente dava prosseguimento aos seus estudos e a concluía cursos de qualificação (Vieira, 2006).

Portanto, dois pontos são primordiais para melhor entendimento sobre inclusão social e esporte para pessoas cegas, sendo estes: a imagem do "eu" para o cego e a relação esporte / cego. A não aceitação de um indivíduo em um grupo, em muitos casos, tem sua origem na rejeição pessoal, acarretando obstáculos para a sua sociabilização (Maciel, 2001; Quintão, 2005; Ribeiro, 2003). Os mesmos afirmam que quando uma pessoa cega não tem conhecimento do seu potencial, nem da estrutura do seu corpo, seu relacionamento com a sociedade torna-se muito mais difícil.

Para Martín e Bueno (1997) existe uma defasagem na primeira infância de uma criança cega em relação a uma criança normal. Nota-se um atraso no desenvolvimento cognitivo e psicomotor, confirmando a maior perda no período sensório-motor, pela necessidade de interagir com o ambiente que o cerca.

Outros autores destacam a importância da prática esportiva durante a primeira fase de vida do cego, sendo esta primordial para a sua relação com o psiquismo e o desenvolvimento cognitivo, diretamente relacionado na sua conduta na fase adulta (Martín \& Bueno, 1997; Rechineli, Porto, \& Moreira, 2008).

Cratty e Thereza (1984) estudaram o comportamento de uma menina cega com seu irmão gêmeo, normovisual. Perceberam que a irmã cega não teve oportunidade de receber informações sobre seus atributos motores, constatadas na investigação através de testes motores e cognitivos. Para Rechineli e colaboradores (2008) uma boa imagem corporal é essencial para uma efetiva capacidade motriz.

Contudo a prática esportiva desenvolvida por atletas cegos é pouco conhecida pela sociedade, sendo este um dos caminhos investigados por Pereira (2008) para a inclusão desta clientela nas discussões sobre o Desenvolvimento Sustentável. Além disso, este entre outros estudos apontam para os benefícios da prática esportiva no desenvolvimento motor e cognitivo do cego, refletindo ainda na qualidade de vida e no cotidiano dessas pessoas (Pereira, 2008; Maciel, 2001; Rechineli et al., 2008).

Nesse sentido, o estudo de Monteiro (1999) utilizou vinte e quatro indivíduos cegos congênitos, praticantes e não praticantes de atividade física. Chegou à conclusão que os indivíduos praticantes de atividade física possuíam uma influência positiva na amplitude da passada, melhor desenvolvimento da orientação espacial e melhor conhecimento do próprio corpo.

Outro estudo sobre os benefícios da atividade física para cegos foi realizado em Porto Alegre - Rio Grande do Sul. Ribeiro (2003) estudou duas pessoas cegas, uma de cada sexo, concluindo que a atividade física diminuía o nível de depressão e ansiedade, contribuindo 
para a melhora na auto estima. Brancatti, Viana, e Vilela (2001) fizeram um estudo similar em Presidente Prudente, São Paulo, chegando a mesma conclusão.

Outra justificativa para a importância da prática esportiva para cegos é o trabalho com a reabilitação de pessoas que ficam cegas, na fase adulta e são atendidas no IBC. Nesta reconstrução social a prática esportiva se faz presente com grande êxito, por caracterizar atividades grupais, acessíveis a todos e melhorando a auto estima.

Franco (2001) relata que a reabilitação de uma pessoa cega, será uma reorganização total de sua vida, diante da perda deste sentido. Esta reorganização implica na readaptação física, psicológica, social e profissional como um todo, e durante este processo vivência momentos de revolta, ansiedade, angústia e negação da deficiência sem esperança de cura e descreve a importância da prática esportiva neste processo de reabilitação.

Para Guaragna, Pick, e Valentini (2005) e Rechineli et al. (2008) o desenvolvimento social origina-se na prática esportiva, desenvolvendo habilidades de comunicação, na troca de idéias e na superação das dificuldades, reforçando a confiança.

Guaragna et al. (2005) crêem na prática esportiva como ferramenta para aperfeiçoar as relações sociais entre as crianças, diminuindo as atitudes auto agressivas, percebidas geralmente após frustrações, rejeições, ansiedade e tensão.

Desta forma, percebemos que a prática esportiva contribui na melhoria de vários aspectos, em todas as faixas etárias (Guaragna et al., 2005; Labronici, Cunha, Oliveira, \& Gabbai, 2000; Pereira, 2008; Rechineli et al., 2008; Vieira, 2006), principalmente sendo utilizada para o benefício social da população de deficientes visuais no Brasil.

A prática esportiva de alto rendimento proporciona oportunidades para o indivíduo deficiente desenvolver as suas potencialidades, sentir alegria e prazer, experimentar o sucesso e superar os seus limites (DePauw \& Gavron, 2005). Por outro lado, estes desportistas funcionam como modelo de superação para outros indivíduos com deficiência, estimulando-os na busca de soluções para ultrapassar as suas próprias barreiras, facilitando a integração na sociedade (Winnick, 2005; Woods, 2008).

A prática esportiva contribui para a sociabilização da pessoa com deficiência na medida em que facilita a comunicação, a realização pessoal, a auto-imagem, o auto-conceito e a autonomia, além de relativizar as suas limitações, uma vez que valoriza e divulga as suas capacidades físicas. Promove assim uma acentuação das capacidades em desfavor das limitações. O desporto também reforça a auto-estima, dando-lhe alegria de viver, melhorando a qualidade de vida, favorecendo a comunicação e o convívio social.

Vários autores (Bento, 2004; Bodas, Lázaro, \& Fernandes, 2007; Garcia \& Lemos, 2005; Marques, Castro, \& Silva, 2001; Winnick, 2005) evidenciam os benefícios psicológicos, físicos, fisiológicos, sociais, entre outros, do desporto para a pessoa com deficiência.

Hamel (1992) e Sherrill (1986) alertam para este envolvimento do esporte praticado por pessoas deficientes e o esporte praticado por atletas convencionais. Os autores afirmam a contribuíção satisfatória na troca de atitudes sobre a capacidade das pessoas deficientes perante a sociedade.

A prática esportiva para pessoas com deficiência procura também o rendimento. O treinamento de alto rendimento para deficientes carreia consigo metas facilitadoras de problemáticas sociais, tais como conscientizar a sociedade para a inclusão, com ações voltadas para a qualidade de vida, a superação do preconceito e o cultivo da solidariedade.

West (1994) e Nixon (1989) reforçam este pensamento exemplificando provas com a participação de atletas convencionais e atletas em cadeiras de rodas. Os autores citam a Maratona de Boston e a Maratona de Nova York, cuja participação conjunta oportuniza a inclusão, mas 
chamam a atenção que esta ideia ainda encontra resistência por parte da organização destes eventos, baseado em questões de segurança.

Brasile (1990) reforça que as provas conjuntas, com deficientes e não deficientes, devem ser valorizadas pela possibilidade dos benefícios de reintegração social. Concordamos com o valor das provas conjuntas, mas entendemos que a competição envolve comparação e nesse caso os deficientes estão em desvantagem em relação aos não-deficientes, sendo impossível aferir quem são os melhores. Nas provas conjuntas o deficiente será reconhecido por sua participação, mas não tem a chance de ser o vencedor. Só em condições semelhantes aos oponentes é possível vivenciar a vitória, de acordo com marcas e resultados.

O ícone do desporto de alto rendimento para deficientes é a Paraolimpíada, sendo esta uma conquista para o segmento, demonstrando ao mundo o potencial dos deficientes. Portanto é uma oportunidade ímpar de mostrar uma imagem positiva para seus pares, que ainda sentem vergonha de suas deficiências (Vieira, 2006).

No Paraolimpismo, as ideias de rendimento e de superação estão igualmente representadas, constituindo um verdadeiro apelo à máxima citius, altuis, fortius (mais veloz, mais alto e mais forte). A pessoa com deficiência ao superar-se está igualmente vencendo preconceitos e tabus. Tal como afirmam Garcia e Lemos (2005), tem pela frente um duplo desafio. O primeiro é o ato de praticar uma atividade física com poucas oportunidades e o segundo treinar cada vez mais para superar seus adversários.

$\mathrm{Na}$ perspectiva de melhorar a qualidade de vida das pessoas cegas, usando como amostra atletas do Instituto Benjamin Constant (IBC), esta investigação estudou a relação do esporte como fator transformador na vida dessas pessoas, direcionando-os para a sociabilização, assim como a aceitação de suas deficiências, sendo este um dos maiores problemas do contexto social brasileiro atual.
O IBC é um órgão da administração direta do Ministério de Educação do Brasil, tendo a competência, dentre outras, de promover a educação de deficientes visuais e cegos, visando possibilitar o pleno exercício da cidadania e o resgate da imagem social desses indivíduos.

Foi relevante neste estudo dar "voz" ao grupo de atletas cegos do IBC, nos aspectos positivos e negativos de suas vidas com relação à inclusão social, oportunizando investigar a sua capacidade de participação.

Nessa perspectiva, optamos pela utilização de uma metodologia de perfil qualitativo uma vez que, devido às suas potencialidades (Denzin \& Lincon, 2000; Strauss \& Corbin, 1998), pode proporcionar um conjunto de dados que nos ajudem a compreender as percepções e entendimentos que estes atletas apresentam relativamente a sua inclusão social.

$\mathrm{Na}$ tentativa de possibilitar um melhor entendimento e através da convivência de parte dos autores desta investigação há mais de uma década e meia no IBC, notando a diferença entre alunos cegos e os atletas cegos, no que diz respeito as suas vidas, este estudo surgiu com a indagação: qual a importância do desporto de alto rendimento para os atletas cegos do IBC na inclusão social?

Com esta indagação surge o objetivo geral, sendo este: investigar como o esporte de alto rendimento melhorou a qualidade de vida e facilitou a inclusão social desses indivíduos na sociedade brasileira.

A pouca bibliografia existente com o tema desta investigação e ao mesmo tempo relevante socialmente para o segmento em questão, oportuniza as instituições educacionais utilizar deste meio para inclusão social das pessoas cegas.

Desta forma, esperamos os resultados dessa pesquisa sirvam para incentivo de ações voltadas para o desporto para deficientes, fazendo deste uma ferramenta para inclusão social, já que no Brasil esta prática é muito difundida. 


\section{MÉTODo}

\section{Amostra}

Este artigo decorre de um projeto de pesquisa de Mestrado em Ciências da Atividade Física da Universidade Salgado de Oliveira (UNIVERSO) no Brasil. O local da pesquisa foi o IBC, Referência Brasileira nas questões da pesquisa, aprendizagem e fomento do desenvolvimento integral dos cegos e deficientes visuais.

Nesta pesquisa foram entrevistados dez alunos cegos egressos IBC, do sexo masculino, que vivem nos subúrbios do Município do Rio de Janeiro, selecionados a partir dos seus momentos atuais, isto é, levando em conta sua formação, comprometimento trabalhista e a satisfação em suas realizações atuais, com média de faixa etária de $32.5+7.5$ anos.

Os participantes fazem parte de Associações que disputam os campeonatos organizados pela Confederação Brasileira de Desporto de Deficientes Visuais (CBDV) desde 1994, nas modalidades de natação, atletismo, futebol cinco, judô, xadrez e goalball (esporte específico para deficientes visuais).

Para definição dos atletas cegos, utilizou-se a classificação oftalmológica da CBDV, que é instituída pela Associação Internacional de Esporte para Cegos (IBSA), para legitimar ou não a participação de um atleta deficiente visual e cego, nas competições oficiais nacionais e internacionais. Os participantes deste estudo são atletas B1(cegos), sendo que $70 \%$ adquiriu a cegueira através do glaucoma e $40 \%$ é cego congênito e $60 \%$ ficaram cegos com idade média de $10+2$ anos .

A maioria dos atletas entrevistados fazem parte da equipe de Futebol de 5 do IBC, com alguns integrantes das equipes de goalball, atletismo e natação. Parte desta amostra representa o Brasil em campeonatos internacionais, como as Paraolimpiadas, Mundiais e Parapanamericanos.

Hoje, em um panorama mundial do esporte para deficientes visuais, o Brasil está entre as nove maiores potências. A título de esclareci- mento, o Brasil ficou em nono lugar na última Paraolimpida (2008), dentre 142 países e foi o campeão no último Parapanamericano, em Guadalajara - México (2011), ficando a frente de potências esportivas como Estados Unidos e Canadá. No judô masculino temos o atual campeão Mundial e Paraolímpico; no futebol somos Campeões Mundiais (1998, 2000 e 2010), Paraolímpicos (2004 e 2008) e Panamericanos (2007 e 2011); no atletismo temos o recordista mundial nos 100 e 200 metros rasos, e a campeã Paraolímpica (2008) das mesmas provas, além de disputarmos grande parte das finais nos esportes individuais destes campeonatos.

Enfim, esta amostra faz parte de um grupo de atletas que representam o Brasil em competições internacionais, oriundos do IBC, contribuindo com seus depoimentos para esclarecer a importância do esporte em suas vidas e a relação deste com a inclusão social.

\section{Instrumentos}

$\mathrm{O}$ instrumento utilizado foi a entrevista semi-estruturada, que envolve perguntar questões previamente estabelecidas, assim como questões formuladas no momento da entrevista (Creswell, 1994; Flick, 2005; Minayo et al., 2002; Neto, 2002; Ruquoy, 2005).

O guião da entrevista foi realizado em uma pesquisa de Mestrado (Pereira, 2008), a partir dos objetivos específicos da pesquisa, que eram: 1) investigar como o esporte promoveu a inclusão social do deficiente visual do IBC; 2) destacar quais foram as principais diferenças entre a vida antes e depois da prática de esporte de alto rendimento; 3) investigar a influência do esporte na qualidade de vida dos participantes do estudo 4) apontar quais os benefícios que o conceito de Desenvolvimento Sustentável (DS) trouxe ou trará para sua vida; e 5) mostrar qual é o papel do deficiente visual nas discussões sobre o DS. Porém, neste artigo, excluímos a temática do desenvolvimento sustentável.

Seus requisitos foram elaborados de acordo 
com vários autores (Bogdan \& Birklen, 1994; Ghiglione \& Matalon, 2001; Quivy \& Campenhoudt, 1998; Ruquoy, 2005). Para aprimoramento do guião da entrevista Pereira (2008) realizou um estudo piloto com dois alunos atletas do IBC, que participaram do Campeonato Brasileiro de Futebol 5 em Campina Grande - Paraíba.

Após este processo procedemos a determinados ajustamentos. Verificado que não havia mais dúvidas sobre o que se pretendia, elaborou-se a versão final da entrevista. Antes da sua aplicação aos sujeitos do estudo, o guião da entrevista foi submetido a um grupo de professores do ensino superior, habituados a lidar com este tipo de instrumento, que o sancionou. A entrevista foi então aplicada aos dez atletas, participantes da pesquisa (Pereira, 2008).

\section{Procedimentos}

Para ordenar os procedimentos metodológicos adotados na presente investigação, utilizou-se as orientações de Alves-Mazzotti e Gewandsznajder (2004), Flick (2005) e Thomassim (2007). Nesse sentido, as entrevistas foram feitas no ambiente de treinamento dos entrevistados, compreendendo ginásios, piscinas, pistas de atletismo, mas de forma reservada para não sofrer nenhum tipo de influência externa e ao final de seus treinamentos.

Para maior confiabilidade do estudo, foram seguidas as sugestões de Alves-Mazzotti e Gewandsznajder (2004) e Thomassim (2007) no que diz respeito ao esclarecimento das inclinações do pesquisador e a verificação dos participantes. O estudo seguiu a Resolução 196/96 do Conselho Nacional de Saúde do Brasil que informa sobre as diretrizes e normas regulamentadoras de pesquisas envolvendo seres humanos. Considerando o deficiente visual independente e capaz, em vários aspectos da vida cotidiana, o termo de consentimento livre e esclarecido foi confeccionado em Braille, para maior independência dos entrevistados.

Todas as entrevistas foram gravadas com a devida autorização no ambiente do treinamento específico de cada atleta, sendo transcritas e lidas a posteriori aos entrevistados, que pouco as modificaram. A transcriçãa dessas entrevistas constituiu o corpus de análise deste estudo.

A técnica de tratamento das informações foi a "Análise de Conteúdo" através das entrevistas, classificadas em categorias, seguindo as orientações de Minayo, Deslandes, Neto, e Gomes (2002) de formular categorias iniciais antes do trabalho de campo e reformulá-las na fase de coleta e análise dos dados.

Para formular as categorias utilizamos primeiro a análise cross-question, que analisa cada entrevista individualmente provendo ao pesquisador uma ideia da complexidade de cada entrevista. Após essa etapa, utilizamos a análise cross-interview, visando comparar as entrevistas para encontrar as similaridades e diferenças entre as respostas dos entrevistados (Mayring, 1994, citado por Schilling, 2006).

A redução dos dados também chamada de condensação dos dados é uma forma de análise que separa, seleciona, sintetiza e organiza. A exposição dos dados consiste em organizar de uma forma compacta um conjunto de informações (Miles \& Huberman, 1994). Com esses dois princípios foi criado um quadro com categorias e sub-categorias, que serviu para visualizar o conjunto de resultados da pesquisa, dos quais para esse artigo selecionamos três sub-categorias.

Ao analisarmos as entrevistas efetuadas aos atletas cegos, as ideias que encontramos presentes de uma forma bem clara, são «a importância do esporte», "O esporte e a orientação e mobilidade» e «a vida antes e depois de ser atleta». Estas ideias ou mensagens transparecem em muitas das "falas" dos entrevistados emergindo assim como categorias decisivas deste estudo. Estas, no seu conjunto, definem o quadro de preocupações, valores e atitudes que configuram a inclusão social destes atletas. 


\section{RESULTADOS E DISCUSSÃO \\ A importância do esporte}

Para melhor entendimento sobre o estudo, investigou-se a importância do desporto na vida dos atletas cegos de alto rendimento do IBC, partindo, daí, para outros questionamentos. Todos deram grande relevância a prática esportiva, confirmando alguns estudos (Guaragna et al., 2005; Ruquoy, 2005; Vieira, 2006). O entrevistado 1 falou da seguinte forma:

"a prática esportiva melhorou o meu desenvolvimento psicológico, meu desenvolvimento intelectual, meu desenvolvimento de percepção de espaço, enfim todas as minhas faculdades, sejam elas físicas ou mentais".

Os entrevistados 2 e 3 foram apontaram para outro benefício da prática esportiva, a orientação e mobilidade. O seu exercício facilita a "independência" da pessoa cega na sua rotina diária nos locais de sua convivência.

Tão importante quanto a locomoção facilitada, foi a declaração do entrevistado 3 sobre a contribuição do esporte para melhoria do relacionamento interpessoal, frisando: "o esporte nos ensina no dia a dia, como lidar com as pessoas. A gente acaba conhecendo muita gente e sabendo lidar com as mais diversas pessoas".

A declaração do entrevistado 5 mostrou um exemplo de superação. Este entrevistado ficou cego na fase adulta, através de um acidente automobilístico e teve que reeducar sua vida com ausência da visão. Com bastante afinidade neste assunto Labronici et al. (2000), comenta que a prática esportiva direciona para uma melhor integração social e melhor aceitação da deficiência.

Ele declara o esporte oportunizando-o a situações que quando era normovisual nunca imaginou em realizar. Ele descreve:

"o esporte deu um incentivo para lutar por aquilo que eu desejo; por traçar metas a serem alcançadas efetivamente e lutar por aquilo que eu sonho. Quando nós fomos inseridos no contexto de competições, você consegue obter vitórias e conquistas, percebendo que é capaz de alçar vôos mais altos, vislumbrando novos desafios que se tornarão conquistas no futuro. Para pessoas portadoras de deficiência visual foi muito importante eu me inserir no contexto esportivo, isso me fez ver a vida com outros olhos, sem trocadilhos, mas foi um recomeço de um modo geral. A partir daí, eu comecei a evoluir como pessoa, como cidadão e como ser humano também."

Os entrevistados 6, 8, 9 e 10 responsabilizam o esporte como principal responsável para melhoria da auto-estima, como nos estudos de Guaragna et al. (2005), Labronici et al. (2000) e Rechineli et al. (2008).

No depoimento do entrevistado 6 declara ter sido um menino amedrontado por ficar cego e conseqüentemente diferente de todos os outros da sua vizinhança. Através do esporte ele aprendeu a aceitar a ausência da visão, realizando seus sonhos infantis. Ele narra assim:

"O esporte ajuda na auto-estima. Quando eu me vi cego [...] fiquei muito triste e era muito pequeno. Eu não conseguia entender porque as pessoas enxergavam e eu não. Aquele medo de você ser o único diferente do mundo. Estudando no Benjamin (IBC) passei a conhecer o esporte, percebendo que eu não só poderia ser feliz, como útil. [...] com o treinamento passei a competir concretizando a afirmativa que o esporte abriu as portas para mim."

O entrevistado 7 correlaciona a prática do esporte como motivador e disciplinador de suas ações em sua vida. Relata que através da disciplina dos treinamentos, o esporte conscientiza o atleta a respeitar o próximo, a conquistar os seus sonhos e interagir com o próximo. Para Quintão (2005), a sociedade percebe na pessoa deficiente o sinônimo de incapaz, o que pouco percebemos é que todos nós somos imperfeitos. Tal como nos diz Bento (2004, p.85), "chamam-lhes deficientes e, ao dizê-los assim, julgam-se normais os que o não são. Mas não. São atletas e homens especiais. Porque deficientes somos todos nós". 


\section{O esporte e a orientação e mobilidade}

A pesquisa investigou a questão do esporte como contribuição para "independência" do cego, tendo a orientação e mobilidade como uma meta a ser alcançada. Desta forma, perguntou-se se o esporte possibilita a melhoria da orientação e mobilidade, sendo esta uma condição básica para independência nos ambientes em que transita. A resposta foi unânime em afirmar grandes melhorias.

O entrevistado 1 acrescentou que através da prática esportiva de alto rendimento melhorou a sua orientação e mobilidade, possibilitando melhor domínio sobre seu corpo. Ele afirmou que a partir desta prática, conheceu melhor suas limitações e conseguiu acompanhar suas progressões funcionais. Finalizou a declaração, dizendo:

"se eu tenho a capacidade de jogar bola, de pular em uma piscina e correr numa pista de atletismo, eu tenho totalmente a capacidade de sair numa rua e chegar a um lugar que eu quero chegar, sozinho ou com o mínimo de ajuda possível; isso graças ao esporte".

Dando a mesma importância a prática esportiva o entrevistado 2 declarou que nunca precisou fazer uma aula de orientação e mobilidade, pois a prática esportiva lhe proporcionou esta habilidade, contribuindo para sua independência. Citou como exemplo o atravessar a rua e descreveu:

"as travessias são movimentadas, e é óbvio que as pessoas avançam em grupos numerosos, não permitindo que os carros avancem o sinal; então, pela audição e por tudo que a gente desenvolve no esporte, atravessamos numa boa a rua, até sem ter uma pessoa diretamente nos auxiliando, e isso é uma forma de independência".

O entrevistado 8 deixou bem claro a melhoria da sua orientação e mobilidade, sendo muito enfático na contribuição do esporte nesta aquisição pessoal, a independência parcial de sua locomoção, relatando:

"O esporte me proporcionou inicialmente a independência. Porque saímos da 'saia da mãe' para você fazer as coisas sozinho. [...] e no esporte, eu comecei a desenvolver a motricidade, o intercambio, a independência e até a melhorar a minha auto-estima [...] através das competições esportivas, percebia que existia outros cegos que eram independentes e certamente eu me cobrava para ser como eles. Essa experiência de perceber que existem outros cegos que são independentes, trabalhando, tendo suas famílias e felizes, certamente foi um marco em minha vida, que o esporte proporcionou."

O entrevistado 9 conseguiu distinguir o seu estado sedentário antes da prática esportiva. A partir dos treinamentos, ele afirmou ter melhorado a qualidade de vida, a independência, a auto-estima e a orientação e mobilidade; talvez o mais importante foi a perda do medo em solicitar informações e ajuda. Neste trecho de sua entrevista ele descreveu:

"com os treinamentos eu achei que comecei a ter uma qualidade de vida melhor, mais animado, mais independente, inclusive na melhoria da minha orientação e mobilidade, sendo esta essencial para o meu deslocamento nas ruas do Rio de Janeiro. [...] Pelo esporte ser disciplinador você acaba transferindo para seu dia a dia facilitando a execução de nossas tarefas. No nosso caso especifico, quando começamos a andar sozinhos, existe uma certa restrição em pedir ajuda e o esporte ensina a viver em conjunto, ajudando uns aos outros, quebrando esta dificuldade gerada através da inibição, solucionada muitas vezes em solicitar uma informação no ponto do ônibus, o que antes esperávamos que alguém prestasse este atendimento."

Autores como DePauw e Gavron (2005), Guaragna et al. (2005), Lieberman (2005), Nuernberg (2008), Rechineli et al. (2008) e Vieira (1998) reconhecem estas dificuldades e sugerem a prática esportiva como meio dinamizador de vários benefícios para o cego. 


\section{A vida antes e depois de ser atleta}

Sobre a diferença entre antes e depois de serem atletas de alto rendimento, todos enfatizaram a questão das melhorias individuais como a locomoção, a orientação e ao fator cognitivo, o que os tornou mais ativos.

O entrevistado $1 \mathrm{fez}$ uma projeção do que seria sua vida se não fosse atleta: "eu acho que eu teria que desenvolver outras formas para ter os êxitos que eu tive praticando o esporte; a partir daí, eu não sei, teria uma vida sedentária".

Quando Vygotski (Nuernberg, 2008) comenta em seus textos que o deficiente visual deve buscar outras alternativas para compensar a ausência da visão, vem de encontro a esta declaração, em que busca alternativas para normatizar sua convivência.

O entrevistado 2, confunde a vida antes e depois de ser atleta, com a vida antes e depois de ser alfabetizado no IBC. Mas, apesar da transferência de foco, aponta para um detalhe muito importante, que o esporte de alto rendimento o fez participar muito mais, não só entre os deficientes visuais, mas com todas as pessoas do meio em que vive.

O entrevistado 3 detectou a diferença, entre antes e depois de ser atleta, por sua inclusão nos grupos sociais pelos lugares por onde competiu, melhorando sua relação interpessoal.

O entrevistado 4 teve a percepção clara a respeito desta questão, determinando precisamente seu comportamento antes e depois do treinamento de alto rendimento, declarando:

"eu tenho o esporte como uma linha de referência, onde antes dele eu tinha um comportamento mais retraído, e depois da prática esportiva, das viagens das competições e do meu convívio com outras pessoas de outras culturas, eu pude me tornar mais descontraído na minha relação com outras pessoas; por esta razão eu afirmo que o esporte me possibilitou um relacionamento melhor com as pessoas."

Cavalcante e Minayo (2009) e França e Pagliuca (2009) em suas investigações sobre os desafios de pessoas deficientes, apresentam como um deles o reconhecimento como cidadão, e sugerem que os órgãos governamentais tenham o mínimo de convivência com esses grupos para implementar ações mais efetivas para inclusão. É certo que, se o deficiente não se impor, reclamar, reivindicar, difícil será escutá-los. Neste depoimento percebece a importância da prática esportiva na melhoria da auto estima e confiança, resultando no melhor convívio social.

Assim como os entrevistados 4 e 7 , o entrevistado 5 é o caso da perda da visão na fase adulta. O entrevistado descreve:

"antes eu tinha uma vida sem sonhos a realizar, estando satisfeito no patamar em que me encontrava. Com a perda da visão, eu entrei no IBC e comecei a fazer um trabalho de reabilitação, o qual me trouxe a prática esportiva e a partir daí comecei a enxergar novos horizontes e a buscá-los. Eu saí de um nível do terceiro ano primário incompleto e depois de cego, aí já esportista, completei o primeiro grau, o segundo grau e hoje estou prestes a concluir o terceiro grau em Direito. Isso tudo motivado pela prática esportiva."

Os entrevistados 6 e 10 declararam um benefício muito consistente: o esporte como inibidor do medo. Este medo é relatado por eles no momento da perda da visão, quando ainda eram crianças, sendo trabalhado com a prática esportiva. Labronici et al. (2000) e Rechineli et al. (2008) constatam esta mudança em seus estudos. Rechineli et al. (2008) descreve outros fatores benéficos da prática esportiva como a independência, a concentração, a integração social, a vida mais ativa e o respeito às regras comunitárias. O entrevistado 6 explica assim esta temática:

"Eu acho que a palavra chave é o medo. O medo não existe mais. Eu hoje sou inserido na sociedade como um cidadão sem medo. Não sei se todo o deficiente, mas eu quando fiquei deficiente tinha muito medo de chegar nas pessoas; não tinha idéia como elas iam me receber. 
Naquele instante eu me achava inútil. No momento que você percebe que está praticando esporte, sendo tão bom quanto as pessoas que enxergam, no seu desporto, você começa a perceber que você também é bom, perdendo o medo de todos e chegando a conclusão que todos são iguais a minha pessoa, mudando radicalmente a minha vida."

O entrevistado 8 reforça a condição de independente, aprendida através dos treinamentos, deixando bem claro a sua importância, assim como um marco em sua vida. Ele diz:

"o divisor de águas foi ficar independente através do esporte. Eu tinha uma dependência muito grande com minha família [...] com 14 anos, quando eu comecei a treinar com mais afinco, dispensei todo esse auxílio, o que me deu autoconfiança [...] refletindo em todas as minhas tarefas do dia. E tudo isso eu devo ao esporte, porque se eu conseguia vencer dentro da quadra eu conseguiria também vencer na vida, melhorando muito a minha auto-estima."

Estas afirmações confirmam as indicações de autores como Cavalcante e Minayo (2009), DePauw e Gavron (2005), França e Pagliuca (2009), Guaragna et al. (2005), Labronici et al. (2000), Lieberman (2005), Rechineli et al. (2008) e Vieira (2006), sobre as questões voltadas para integração social do deficiente a partir da melhoria da auto estima e a prática esportiva leva a obtenção desta finalidade.

\section{CONCLUSÕES}

Esta investigação, conclui que o esporte de alto rendimento contribui para o atleta cego estar incluído socialmente. Suas entrevistas nos asseguram o preconceito existente em suas vidas, mas minorizadas com o exercício da prática esportiva.

Constatou-se que a prática do esporte de alto rendimento foi um instrumento importante no cotidiano dos atletas do IBC, resultando na melhoria da auto estima e na motivação, conseqüentemente em outras virtudes estimuladas e aprendidas, facilitando a inserção social.
A presente investigação mostra a eficiência e não a deficiência, oportuniza a igualdade e a aceitação entre todos, permite referenciar a independência parcial do cego, tendo como objetivo maior o exercício da cidadania. Para maior reflexão e alerta, esta investigação sugere maior atenção para todos os segmentos negligenciados socialmente nas questões de justiça social, direitos e respeito às resoluções surgidas de seus próprios representantes. Alertamos ainda, que de forma alguma responsabilizamos o esporte como o único instrumento de acesso à inclusão social dos cegos, mas apenas como um dos meios.

Esta investigação recomenda pesquisas voltadas para inclusão deste segmento, oportunizando os deficientes a expor suas problemáticas, dando voz ao segmento, enfim, legitimar o deficiente como cidadão.

Agradecimentos:

Nada declarado.

Conflito de Interesses:

Nada declarado.

Financiamento:

Nada declarado.

\section{REFERÊNCIAS}

Alves-Mazzotti, A. J., \& Gewandsznajder, F. (2004). O método nas Ciências Naturais e Sociais: Pesquisa qualitativa e quantitativa. São Paulo: Thompson.

Bento, J. (2004). Desporto. Discurso e Substância. Porto: Campo das Letras, Ed. S.A.

Bodas, A., Lázaro, J., \& Fernandes, H. (2007). Perfil psicológico de prestação dos atletas paralímpicos Atenas 2007. Motricidade, 3(3), 33-43.

Bogdan, R., \& Birklen, S. (1994). Investigação qualitativa em educação. Uma introdução à teoria e aos métodos. Porto: Porto Editora.

Brancatti, P. R., Viana, E. S., \& Vilela, R. C. A. (2001). Atividade motora adaptada para pessoas deficientes visuais. Paraná: Universidade Estadual de Londrina. 
Sherrill, C. (1986). Sport and Disabled Athetics (pp.181-187). Champaign: Human Kinetics.

Brasile, F. M. (1990). Wheelchair sports: A new perspective on integracion. Adapted Physical Activity Quarterly, 7, 3-11.

Cavalcante, F. G., \& Minayo M. C. S. (2009). Social representations of rights and violence in the disability field. Revista Ciência \& Saúde Coletiva, 1, 38-47.

Cratty, J. B., \& Theresa, A. S. (1984). La imagen corporal de los niños ciegos. Cordoba - Argentina: International Council for Education of the Visually Handicapped.

Creswell, J. (1994). Research design. Qualitative \& quantitative approaches. London: Sage Publications.

Denzin, N., \& Lincon, Y. (Eds). (2000). Handbook of Qualitative Research (2nd ed.). London: Sage Publications.

DePauw, K., \& Gavron, S. (2005). Disability sport (2nd Edition). Champaign: Human Kinetics.

Flick, U. (2005). Métodos qualitativos na investigação científica. Lisboa: Monitor - Projectos e Edições.

França, I. S. X., \& Pagliuca, L. M. F.(2009). Social inclusion of disable people: Achievements, challenges and implications for the nursing area. Revista da Escola de Enfermagem da USP, 2, 16-34.

Franco, J. R. (2001). Intervenção psicológica no processo de reabilitação de adolescentes e adultos com deficiência visual. Paraná: Universidade Estadual de Londrina.

Garcia, R., \& Lemos, K. (2005). Temas (quase éticos) de Desporto. Belo Horizonte: Casa da Educação Física.

Ghiglione, R., \& Matalon, B. (2001). O Inquérito. Teoria e prática ( $4^{\mathrm{a}} \mathrm{ed}$.). Oeiras: Celta Editora.

Guaragna, M. M., Pick, R. K., \& Valentini, N. C. (2005). Percepção de pais e professores da influencia de um programa motor inclusivo no comportamento social de crianças portadoras e não-portadoras de necessidades especiais. Revista Movimento, 1, 89-117.

Hamel, R. (1992). Guetting into the game: New opportunities for athetes with disabilities. The Physician and Sportsmedicine, 20, 121.
Labronici, R. H., Cunha, M. C., Oliveira, A. S., \& Gabbai A. A. (2000). Esporte como fator de Integração do deficiente físico na sociedade. Revista Arquivos de Neuro-Psiquiatria, 2, 46-55.

Lieberman, L. (2005). Visual impairments. In J. Winnick (Ed.), Adapted Physical Education and Sport (4th edition, pp. 205-220). Champaign: Human Kinetics.

Maciel, M. R. C. (2001). Portadores de deficiência a questão da inclusão social, Revista São Paulo em Perspectiva, 3, 15-35.

Marques, U., Castro, J. A. M. , \& Silva, M. A. (2001). Actividade física adaptada: Uma visão crítica. Revista Portuguesa de Ciências do Desporto, 1(1), 73-79.

Martín, M. B., \& Bueno, S. T. (1997). Deficiência visual e acção educativa. In R. Bautista (Ed.), Necessidades Educativas Especiais (pp. 317-347). Lisboa: Ed. Dinalivro.

Miles, M. B., \& Huberman, A. M. (1994). Qualitative data analysis: an expanded sourcebook (2nd ed.). Thousand Oaks: SAGE.

Minayo, M. C. S., Deslandes, S. F., Neto, O. C., \& Gomes, R. (2002). Pesquisa social. Petrópolis RJ:Vozes.

Monteiro, A. S. L. S. (1999). Análise da postura e deficiência visual: influência da atividade física organizada de forma regular e sistematizada na postura do deficiente visual congênito. Dissertação de Mestrado, Universidade Estadual do Rio de Janeiro, Brasil.

Neto, O. C. (2002). O trabalho de campo como descoberta e criação. In M. Minayo, S. Deslandes \& O. Neto (Eds.), Pesquisa qualitativa (pp. 36-55). Petrópolis: Ed. Fundação Getúlio Vargas.

Nixon, H. L. (1989). Integracion of disabled people in mainstream sports: Case study of a partially sighted child. Adapted Physical Activity Quarterly, 6, 17-31.

Nuernberg, A. H. (2008). Vygotski's contributions for the education of visually disabled people. Revista Psicologia em Estudo, 2, 23-35.

Pereira, R. (2008). A contribuição do esporte como meio de inclusão dos deficientes visuais nas discussões sobre o Desenvolvimento Sustentável. Dissertação de Mestrado, Universidade Salgado de Oliveira - 
UNIVERSO, Rio de Janeiro.

Quintão, D. T. R. (2005). Algumas reflexões sobre a pessoa portadora de deficiência e sua relação com o social. Revista Psicologia \& Sociedade, 2, 25-48.

Quivy, R., \& Campenhoudt, L. (1998). Manual de investigação em Ciências Sociais ( $2^{\mathrm{a}}$ ed.). Lisboa: Gradiva.

Ribeiro, E. P. (2003). A influência da atividade física nos níveis de depressão e ansiedade dos portadores de cegueira adquirida. Dissertação de Mestrado, Universidade Estadual do Rio de Janeiro, Brasil.

Rechineli, A., Porto, E. T. R., \& Moreira, W. W. (2008). Corpos deficientes, eficientes e diferentes: Uma visão a partir da Educação Física. Revista Brasileira de Educação Especial, 14(2), 45-59.

Ruquoy, D. (2005). Situação de entrevista e estratégia do entrevistador. In C. Albarello, J. Hiernaux, C. Maroy, D. Ruquoy, \& P. Saint-Georges (Eds.), Práticas e métodos de investigação em Ciências Sociais (2a Ed., pp. 84-116). Lisboa: Gradiva - Publicações Lda.

Schilling, J. (2006). On the Pragamatics of Qualitative Assessment. Designing the Process of Content Analysis. European Journal of Psychological Assessment, 22 (1), 28-37.
Strauss, A., \& Corbin, J. (1998). Basics of qualitative research. Techniques and procedures for developing grounded theory (2nd Ed.). London: Sage Publications.

Vieira, C. S. (1998). Influência da prática do judô no comportamento ansioso de adolescentes deficientes. Dissertação de Mestrado, Universidade Estadual do Rio de Janeiro, Brasil.

Vieira, C. S. (2006). Alunos cegos egressos do Instituto Benjamin Constant (IBC) no período de 1985 a 1990 e sua inserção comunitária. Tese de Doutorado, Instituto Fernandes Figueira - FIOCRUZ, Rio de Janeiro.

Thomassim, L. E. C. (2007). Os sentidos da exclusão na bibliografia da Educação Física brasileira. Revista Movimento, 2, 58-69.

West, J. (1994). Federal Implementation of Americans with Disabilities Act,1991-1994. New York: MilbankMmemorial Fund.

Winnick, J. (2005). An introduction to adapted physical education and sport. In J. Winnick (Ed.), Adapted physical education and sport (4th Ed., pp. 3-20). Champaign: Human Kinetics.

Woods, R. (2008). Social issues in sport. Champaign: Human Kinetics.

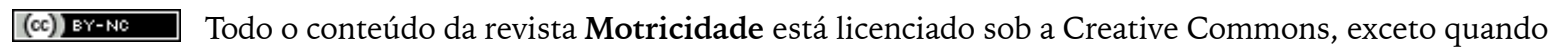
especificado em contrário e nos conteúdos retirados de outras fontes bibliográficas. 